\title{
Does Being Biochemically Euthyroid Guarantee Complete Well-Being among Primary Hypothyroid Patients in Zagazig University Hospital?
}

\author{
${ }^{1}$ Mahmoud A. Sharafeddin, ${ }^{2}$ Amany Mohammed AbdAllah, ${ }^{3}$ Hanaa A. Nofal, ${ }^{1}$ Amr Samir \\ ${ }^{1}$ Internal Medicine Department, ${ }^{2}$ Family Medicine Department, ${ }^{3}$ Public Health and Preventive \\ Medicine, Faculty of Medicine, Zagazig University, Egypt.
}

\section{Abstract}

Background: Hypothyroidism is one of the commonest hormonal deficiencies, which is associated with high somatic and psychiatric morbidity. Objective: This study was done to assess quality of life (QoL), satisfaction with life and treatment among hypothyroid patients and to correlate level of control, disease duration and free Triiodothyronine (T3)/Thyroxine (T4) ratio to these outcome measures. Method: A cross-sectional study was applied on 257 hypothyroid patients in Zagazig University hospital from September 2019 to March 2020. All patients filled in thyroid quality of life, satisfaction with life, thyroid symptom, and satisfaction with thyroid treatment questionnaires. Thyroid profile was assessed. Results: Females represented $66.9 \%$ with mean age 44.175 years. Regarding Thyroid-stimulating hormone (TSH), patients were divided into; uncontrolled, controlled and strictly controlled, which represented $26.5 \%, 35.8 \%$ and $37.7 \%$ respectively. Reduced FT3/FT4 prevailed in $40.5 \%$. There were non-significant relation between level of control and QoL; present, hypothyroid dependent, importance rating or total thyrDol 18 scores. There was statistically significant relation between level of control and each of thyroid treatment satisfaction, satisfaction with life score and thyroid symptom scores. There was statistically significant relation between $\mathrm{T} 3 / \mathrm{T} 4$ ratio and each of present, total thyrDol 18, thyroid treatment satisfaction, satisfaction with life score and thyroid symptom scores. Athyreotic patients had better QoL and SWLS. Conclusion: Achieving biochemical well-being not essentially means physical wellbeing. TSH alone can render patients biochemically euthyroid yet the patients still suffer. Reduced T3/T4 ratio impaired QoL which pointed to importance of development of management strategy rather than relying only on TSH levels.

Keywords: Quality, wellbeing, satisfaction

Corresponding author: Amany Mohammed AbdAllah E.mail: dr.amanymohammed@gmail.com

\section{Introduction}

Clinical primary hypothyroidism is mainly a laboratory-based diagnosis, which is characterized by presence a serum TSH level more than the reference range $(0.4-$ $4.5 \mathrm{mIU} / \mathrm{L})$ and low free $\mathrm{T} 4{ }^{1}$. Hence, diagnosis of primary hypothyroidism exclusively bases on measurement of pituitary $\mathrm{TSH}^{2}$ There is strong evidence that somatic and psychiatric morbidities prevail among those patients, which eventually impaired health related quality of life. ${ }^{3-6}$

Owing to non-specific chronic-like nature of hypothyroid symptoms, it has a noteworthy negative influence on selfreported health status. ${ }^{7}$ Levothyroxine

\section{$\begin{array}{lllll}\text { The Egyptian Journal of Community Medicine } & \text { Vol. } 39 & \text { No. } 4 & \text { Oct. } & 2021\end{array}$}


replacement therapy is the main stay for treatment of hypothyroidism. Therapeutic goals set comprise resolution of symptoms, signs, normalization of serum TSH, and evading overtreatment (iatrogenic thyrotoxicosis), especially in the elderly. ${ }^{2}$ To achieve euthyroid state (by TSH normalization), Free T4 values must be significantly higher than in euthyroid controls. Despite that, serum FT3 is significantly lower than in normal subjects. The patients had an extremely heterogeneous T3 production capacity, suggesting that peripheral $\mathrm{T} 4$ to $\mathrm{T} 3$ conversion may not be appropriate enough to preserve a normal FT3/FT4 ratio using levothyroxine monotherapy. All of that throws patients, into living a sustained state of abnormal thyroid hormone availability for the peripheral tissues, despite normalization of TSH. ${ }^{8}$

\section{Method}

This study was done to assess quality of life, satisfaction with life and treatment among patients with hypothyroidism on treatment and to correlate level of control, disease duration and $\mathrm{T} 3 / \mathrm{T} 4$ ratio to these outcome measures.

A cross-sectional study was recruited on hypothyroid patients attending Endocrine outpatient clinic, Internal Medicine department, Zagazig University hospital from September 2019 to March 2020. All patients attended the clinic during study period and fulfilled inclusion criteria were enrolled.

Case definition: Presence a serum TSH level more than the reference range $(0.4-4.5 \mathrm{mIU} / \mathrm{L})$ and low free T4 (reference range; 0.8 to 1.8 nanograms per deciliter (ng/dL)

Inclusion criteria: Patients with established primary hypothyroidism on treatment with levothyroxine morning dose aged from 18 to 60 years. Normal and overweight pre-obese BMI (from 18 to $\left.29.99 \mathrm{~kg} / \mathrm{m}^{2}\right)$. No other associated comorbidities. With average mentality and ready to cooperate

Exclusion criteria: Secondary hypothyroid patients, Newly diagnosed hypothyroid patients who started replacement therapy for less than 6 weeks, Other comorbidities.

Study tools:

Interviewing questionnaires including Complete history taking, Assessment of socioeconomic level (SES) using ElGilay et al. ${ }^{9}$ : Socio-demographic score less than $50 \%$ (very low and low), score 50\%- less than $75 \%$ (middle) and score $75 \%$ and more (high). The Hypothyroidismdependent quality of life (ThyDQoL): It has with two overview items on present quality of life (present QoL) with scores ranged from excellent (3) to extremely bad $(-3)$ and impact of hypothyroidism on quality of life in general (impact on QoL) that falls in the range from very much better (-3) to worse (1) without disease. The 18-item chief questionnaire evaluates disease impact on different life domains including work or sex life. For each domain, if applicable as the tool involves nine items that can be non-applicable, patients choose whether life in this domain would be very much better $(-3)$ to worse (1) without disease. In addition, they rate the importance of the respective domain from very important (3) to not at all important (0). A weighted domain impact score is calculated by multiplying both ratings for each domain resulting in scores ranging from -9 (maximal negative impact of hypothyroidism on quality of life) to 3 (maximal positive impact of hypothyroidism). The 18-item ThyDQoL had very high internal consistency reliability (Cronbach's alpha $=0.949$,

\section{$\begin{array}{lllll}\text { The Egyptian Journal of Community Medicine } & \text { Vol. } 39 & \text { No. } 4 & \text { Oct. } & 2021\end{array}$}


standardized item alpha $=0.95 .{ }^{10}$ The Thyroid Symptom Rating Questionnaire (ThySRQ) includes fifteen symptoms with

Table (1) Comparison between the studied groups regarding QoL, satisfaction with life, symptom score and satisfaction with treatment:

\begin{tabular}{lr}
\hline \multicolumn{1}{c}{ Baseline data } & \multicolumn{1}{c}{ Total } \\
\cline { 2 - 2 } & \multicolumn{1}{c}{$\mathbf{N = 2 5 7}$} \\
\hline Age (year): & \\
Mean \pm SD & $44.175 \pm 10.336$ \\
\hline Gender: & $172(66.9)$ \\
Female (\%) & \\
\hline SES: & $134(52.1)$ \\
Very low and low & $104(40.5)$ \\
Middle & $19(7.4)$ \\
High & \\
\hline Marital status: & $44(17.1)$ \\
Single & $171(66.6)$ \\
Married & $42(16.3)$ \\
Divorced/widow & \\
\hline BMI (kg/m $\left.{ }^{2}\right):$ & $26.928 \pm 4.416$ \\
Mean \pm SD & \\
\hline Duration (year): & $5(0.5,12)$ \\
Median (min, max) & \\
\hline
\end{tabular}

TSH:

Uncontrolled (TSH $>4.5)$

Controlled (TSH from 2.5 -

$68(26.5)$

$92(35.8)$

4.5)

Strictly controlled $(\mathrm{TSH}<2.5)$

$97(37.7)$

\begin{tabular}{ll}
\hline T3/T4 ratio: & \\
Reduced & $104(40.5)$ \\
Average & $153(59.5)$ \\
\hline Cause: & \\
Disease & $157(61.1)$ \\
Thyroidectomy & $100(38.9)$ \\
\hline
\end{tabular}

a 4-point symptom bother scale indicating how much the symptom bothers them from not at all, a little, quite a bit, very much (scoring 0, 1, 2, and 3, respectively) determining perceived severity of symptoms during the past 3 to 6 weeks. ThySRQ internal consistency reliability was unexpectedly high: Cronbach's alpha $=0.808$, standardized alpha $=0.81 .^{10}$

Thyroid treatment satisfaction-present questionnaire (The ThyTSQ-Present): It is seven-item questionnaire assessing satisfaction with treatment, and control of symptoms over the previous few weeks. Each questions response ranged from 6 to 0 (where 3 is considered a neutral option and 6 very satisfied). Higher scores mean higher satisfaction. ${ }^{11}$ Satisfaction with life questionnaire (SWLS): This five-item tool assesses the perceived satisfaction with life. ${ }^{(12)}$ It includes a 7-point Likert scale ranging from: " $1=$ Strongly disagree" to "7=Strongly agree". The possible range of scores is 5-35, with a score of 20 representing a neutral point on the scale and used as cutoff for evaluating satisfaction. The coefficient alpha for the scale has ranged from 0.79 to $0.89 .{ }^{13}$

All the interviewing questionnaire were translated using bi-lingual expert and tested via backward translation.

\section{Clinical examination}

Laboratory investigation: blood samples were withdrawn in the early morning to measure serum TSH, free T4 and free T3.

Operational design:

Field work: Patients who fulfilled inclusion criteria were interviewed during their visit to the clinic in the waiting room. The interview took 45 minutes to complete history taking, comprehensive clinical examination, answering the interviewing questionnaires. Then patient was sent to clinical pathology department for thyroid profile analysis. Result of thyroid profile was obtained by asking patient to send result to author or on scheduling next visit to clinic. The authors explained and helped illiterate patients to understand question to choose the appropriate answer in their point of view. 
Statistical Analysis

Data analysis was accomplished using the

Table (2) Comparison between the studied groups regarding QoL, satisfaction with life, symptom score and satisfaction with treatment:

\begin{tabular}{|c|c|c|c|c|c|c|}
\hline \multirow{3}{*}{ Parameter } & \multirow[b]{2}{*}{ Total } & \multicolumn{3}{|c|}{ Groups } & \multirow{3}{*}{ Test } & \multirow{3}{*}{$\mathbf{p}$} \\
\hline & & Uncontrolled & Controlled & $\begin{array}{c}\text { Strictly } \\
\text { controlled }\end{array}$ & & \\
\hline & $\mathrm{N}=257$ & $\mathrm{~N}=68$ & $\mathrm{~N}=92$ & $\mathrm{~N}=97$ & & \\
\hline $\begin{array}{l}\text { Present QoL: } \\
\text { Median (min, max) }\end{array}$ & $-2(-3,3)$ & $2(-3,3)$ & $1.5(-3,2)$ & $-2(-3,3)$ & $2.443^{\diamond}$ & 0.295 \\
\hline $\begin{array}{l}\text { Thyroid-dependent } \\
\text { QoL } \\
\text { Median (min, max) }\end{array}$ & $1(-3,1)$ & $0(-3,1)$ & $1(-3,1)$ & $0(-3,1)$ & $2.685^{\diamond}$ & 0.261 \\
\hline $\begin{array}{l}\text { Importance scale: } \\
\text { Median (min, max) }\end{array}$ & $0(-6,6)$ & $0(-6,6)$ & $0(-6,6)$ & $0(-6,6)$ & $2.569^{\diamond}$ & 0.277 \\
\hline $\begin{array}{l}\text { ThyDQoL } \\
\text { item): } \\
\text { Median (min, max) }\end{array}$ & $0(-9,3)$ & $-4(-9,3)$ & $-6(-9,3)$ & $-5(-9,3)$ & $1.358^{\diamond}$ & 0.705 \\
\hline $\begin{array}{l}\text { Thyroid treatment } \\
\text { satisfaction: } \\
\text { Median (min, max) }\end{array}$ & $16(5,35)$ & $11(5,21)^{¥}$ & $19(5,32)^{¥}$ & $22(6,35)^{¥}$ & $73.23^{\diamond}$ & $<0.001 *$ \\
\hline $\begin{array}{l}\text { Satisfaction } \\
\text { (SWLS): } \\
\text { Unsatisfied }(<20) \\
\text { Satisfied }(>20)\end{array}$ & $\begin{array}{r}15560.3) \\
102(39.7)\end{array}$ & $\begin{array}{c}65(95.6)^{¥} \\
3(4.4)\end{array}$ & $\begin{array}{l}45(48.9) \\
47(51.1)\end{array}$ & $\begin{array}{l}45(46.4) \\
52(53.6)\end{array}$ & $48.198^{\infty}$ & $<0.001 *$ \\
\hline
\end{tabular}

Thyroid symptoms

scale

Median (min, max) $\quad 10(1,40) \quad 14(4,40)^{¥} \quad 10(3,38) \quad 8(1,39) \quad 11.578^{\searrow} \quad 0.003^{*}$

${ }^{*} p<0.05$ is statistically significant ¥group responsible for significant difference on pairwise comparison ${ }^{\infty}$ Chi square test ${ }^{\diamond}$ Kruskal Wallis test,.

software SPSS (Statistical Package for the Social Sciences) version 20. Quantitative data was represented using means and standard deviations. Categorical variables were designated using their absolute frequencies, percentages and compared using chi square test. KolmogorovSmirnov (distribution-type) and Levene (homogeneity of variances) tests were utilized to prove suppositions for use in parametric tests. Mann Whitney test (for not normally distributed data) was used to compare continuous variables between two groups. To compare non-parametric continuous variables between more than two groups, Kruskal Wallis test was used. $\mathrm{P}$ value $<0.05$ was considered statistically significant.

\section{Administrative approval}

The study was approved by manager of outpatient clinic and head of Internal Medicine department, faculty of medicine Zagazig University.

Ethical approval

An informed oral consent was obtained from all patients and confidentiality of data was assured. The study was approved by Ethical Committee of faculty of Medicine, Zagazig University.

\section{Result}

About $67 \%$ of patients were females and married. Mean age and BMI were 44.175 years and $26.928 \mathrm{~kg} / \mathrm{m}^{2}$. More than half of them had very low and low SES. Disease

\section{$\begin{array}{lllll}\text { The Egyptian Journal of Community Medicine } & \text { Vol. } 39 & \text { No. } 4 & \text { Oct. } & 2021\end{array}$}


Mahmoud A. Sharafeddin, et al Does being biochemically euthyroid guarantee complete well-being 61

duration ranged from 6 months to 12 years

with median 5 years. Regarding TSH level,

Table (3) Relation between T3/T4 ratio, disease duration and outcome measures:

\begin{tabular}{|c|c|c|c|c|c|c|c|c|}
\hline \multirow{2}{*}{ Parameter } & \multicolumn{4}{|c|}{ T3/T4 ratio } & \multicolumn{4}{|c|}{ Duration } \\
\hline & Reduced & Average & Test & $\mathbf{p}$ & $\leq 5$ years & $>5$ years & Test & $\mathbf{p}$ \\
\hline $\begin{array}{l}\text { Present QoL: } \\
\text { Median (min, max) }\end{array}$ & $-1(-3,3)$ & $2(-3,3)$ & $-2.29^{¥}$ & $0.022 *$ & $-2(-3,3)$ & $-2(-3,3)$ & $-0.815^{¥}$ & 0.415 \\
\hline $\begin{array}{l}\text { Thyroid- } \\
\text { dependent QoL } \\
\text { Median (min, max) }\end{array}$ & $1(-3,1)$ & $0(-3,1)$ & $-1.51^{¥}$ & 0.131 & $1(-3,1)$ & $0(-3,1)$ & $-2.468^{¥}$ & $0.014 *$ \\
\hline $\begin{array}{l}\text { Importance scale: } \\
\text { Median (min, max) }\end{array}$ & $0(-6,6)$ & $0(-6,6)$ & $-1.23^{¥}$ & 0.219 & $0.5(-6,6)$ & $0(-6,6)$ & $-2.13^{¥}$ & $0.021 *$ \\
\hline $\begin{array}{l}\text { ThyDQoL(18 } \\
\text { item): } \\
\text { Median (min, max) }\end{array}$ & $-7(-9,3)$ & $-4(-9,3)$ & $-4.52^{¥}$ & $<0.001 *$ & $-4(-9,3)$ & $-6(-9,3)$ & $-1.448^{¥}$ & 0.148 \\
\hline $\begin{array}{l}\text { Thyroid } \\
\text { treatment } \\
\text { satisfaction: } \\
\text { Median (min, max) }\end{array}$ & $15(6,35)$ & $18(5,33)$ & $-2.13^{¥}$ & $0.033^{*}$ & $18(5,35)$ & $14(5,33)$ & $-1.939^{¥}$ & 0.053 \\
\hline $\begin{array}{l}\text { Satisfaction } \\
\text { (SWLS): } \\
\text { Unsatisfied }(<20) \\
\text { Satisfied }(>20)\end{array}$ & $\begin{array}{l}66(69.5) \\
29(30.5)\end{array}$ & $\begin{array}{l}89(54.9) \\
73(45.1)\end{array}$ & $5.286^{\circ}$ & $0.022^{*}$ & $\begin{array}{l}72(54.5) \\
60(45.5)\end{array}$ & $\begin{array}{l}83(66.4) \\
42(33.6)\end{array}$ & $3.769^{\circ}$ & 0.052 \\
\hline
\end{tabular}

Thyroid

symptoms scale

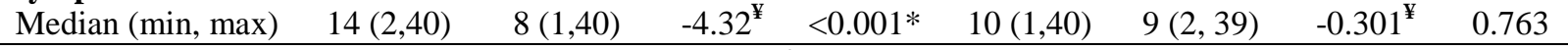

${ }^{*} p<0.05$ is statistically significant $¥$ Mann Whitney test ${ }^{\infty}$ Chi square test

patients were divided into three treatment satisfaction scores, on pairwise

categories: uncontrolled $(\mathrm{TSH}>4.5)$, comparison, the difference is significant

controlled (TSH form 2.5 to 4.5 ) and between each two groups with the strictly

strictly controlled $(\mathrm{TSH}<2.5)$ which controlled group had the best score. The

represented 26.5\%, 35.8\% and 37.7\% uncontrolled group had the worst SWLS

respectively. Concerning $\mathrm{T} 3 / \mathrm{T} 4$ ratio, (only $4.4 \%$ were satisfied) and the highest $40.5 \%$ of patients had reduced ratio (table thyroid symptom score (Table 2).

1).

Regarding satisfaction with life score, only $39.7 \%$ were satisfied. The patients reported scores denoting impaired quality of life, higher thyroid symptom scale, and lower treatment satisfaction scores respectively. There were statistically non-significant relation between level of control and QoL scores; present, hypothyroid dependent, importance rating or total thyrDol 18 scores. There was statistically significant relation between level of control and each of thyroid treatment satisfaction, satisfaction with life score and thyroid symptom scores. Regarding thyroid

There was statistically non-significant relation between level of control and thyroid-dependent QoL and importance rating scores. There was statistically significant relation between $\mathrm{T} 3 / \mathrm{T} 4$ ratio and each of present, total thyrDol 18 (both scores were better in average ratio), thyroid treatment satisfaction, satisfaction with life score (all were higher in average ratio) and thyroid symptom scores (lower in those with average ratio) (Table 3 ).

There was statistically significant relation between level of control and thyroiddependent QoL and importance rating

$\begin{array}{lllll}\text { The Egyptian Journal of Community Medicine } & \text { Vol. } 39 & \text { No. } 4 & \text { Oct. } & 2021\end{array}$


Mahmoud A. Sharafeddin, et al Does being biochemically euthyroid guarantee complete well-being 62

scores. There was statistically non-

significant

Table (4) Relation between cause of primary hypothyroidism and outcome measures:

\begin{tabular}{|c|c|c|c|c|}
\hline \multirow[b]{2}{*}{ Parameter } & \multicolumn{4}{|c|}{ Cause } \\
\hline & $\begin{array}{l}\text { Thyroiditis } \\
\text { N=157 }\end{array}$ & $\begin{array}{c}\text { Thyroidectomy } \\
\mathrm{N}=100\end{array}$ & Test & $\mathbf{p}$ \\
\hline $\begin{array}{l}\text { Present QoL: } \\
\text { Median (min, max) }\end{array}$ & $1(-3,3)$ & $2(-3,3)$ & $-4.232^{¥}$ & $<0.001 *$ \\
\hline $\begin{array}{l}\text { Thyroid-dependent QoL } \\
\text { Median (min, max) }\end{array}$ & $1(-3,1)$ & $0(-3,1)$ & $-3.495^{¥}$ & $<0.001^{*}$ \\
\hline $\begin{array}{l}\text { Importance scale: } \\
\text { Median (min, max) }\end{array}$ & $0(-6,6)$ & $2(-6,6)$ & $-5.299^{¥}$ & $<0.001^{*}$ \\
\hline $\begin{array}{l}\text { ThyDQoL(18 item): } \\
\text { Median (min, max) }\end{array}$ & $-7(-9,3)$ & $-3(-9,3)$ & $-5.722^{¥}$ & $<0.001^{*}$ \\
\hline $\begin{array}{ll}\text { Thyroid } & \text { treatment } \\
\text { satisfaction: } & \\
\text { Median (min, max) } & \\
\end{array}$ & $15(5,35)$ & $18(5,33)$ & $-1.375^{¥}$ & 0.169 \\
\hline $\begin{array}{l}\text { Satisfaction (SWLS): } \\
\text { Unsatisfied }(<20) \\
\text { Satisfied }(>20)\end{array}$ & $\begin{array}{r}106(67.5) \\
51(32.5)\end{array}$ & $\begin{array}{l}49(49) \\
51(51)\end{array}$ & $8.75^{\circ}$ & $0.002 *$ \\
\hline
\end{tabular}

\begin{tabular}{lllll}
\hline $\begin{array}{l}\text { Thyroid symptoms scale } \\
\text { Median (min, max) }\end{array}$ & $10(3,40)$ & $8.5(1,38)$ & $-2.516^{¥}$ & $<0.012^{*}$ \\
\hline
\end{tabular}

${ }^{*} p<0.05$ is statistically significant $¥$ Mann Whitney test ${ }^{\infty}$ Chi square test

relation between T3/T4 ratio and each of

present, total thyrDol 18 , thyroid treatment

satisfaction, satisfaction with life score and thyroid symptom scores (Table 3).

Athyreotic patients had significantly better present QoL, 18-item thyDQoL and better importance rating scales and lower thyroid symptom scales than those with thyroiditis. More than half of them were satisfied with life versus only $32.5 \%$ among those with thyroiditis (Table 4).

\section{Discussion}

In the current study, QoL was impaired regardless TSH level. Even patients with $\mathrm{TSH}<2.5$ did not report significantly better scores. Hence being biochemically euthyroid does not necessarily mean that the patients remain completely normal. QoL, SWLS, treatment satisfaction and symptoms score were significantly related to $\mathrm{T} 3 / \mathrm{T} 4$ ratio, which was reduced in $40.5 \%$ of patients.
Average FT3/FT4 ratio was associated with better QoL scores, satisfaction with life and treatment and thyroid symptom scores. This finding points to importance of T3 level to control patient symptoms and improve well-being.

Hypothyroid patients on levothyroxine therapy who rendered biochemically euthyroid have demonstrated what appears to be residual impairment in QoL as reported in prior research. ${ }^{14}$

A previous study conveyed that using doses of thyroxine that were $50 \mathrm{mg}$ higher than 'optimal' replacement was associated with better wellbeing scores. ${ }^{15}$ However, there are not agreed upon guidelines that support such finding.

Reduced FT3/FT4 ratio represented approximately one third of patients on monotherapy in a prior study. ${ }^{3}$

The concept of tissue hypothyroidism, or hypothyroidism at the cellular level, is not a new emerging concept. It points to the

\section{$\begin{array}{lllll}\text { The Egyptian Journal of Community Medicine } & \text { Vol. } 39 & \text { No. } 4 & \text { Oct. } & 2021\end{array}$}


clinical paradox of symptoms, in spite of biochemical euthyroidism with "optimal" thyroxine dosage. Non-applicability of such concept in clinical field can be attributed to lack of an agreed upon, simple gold standard tool for this measurement ${ }^{15}$ and that the current ATA guidelines recommend against using such tools except for research field. ${ }^{2}$

Lower TSH levels were associated with higher SWLS, lower symptom scores and higher satisfaction with treatment. This may point that high levothyroxine doses can combat lower T3 that made T3/T4 ratio around average values.

Molwwijk et al. ${ }^{16}$ reported persistence of impaired QoL, reduced daily functioning, and residual symptoms, are common in patients in spite of replacement therapy and similar results were reported in prior research. ${ }^{17-18}$

In disharmony with the current finding, Winther et al. ${ }^{19}$ reported that QoL of hypothyroid patients significantly improved after six months after levothyroxine therapy.

The finding agreed with an emerging revolution on traditional treatment of hypothyroidism. The conditional equilibrium formed between TSH and FT4 is called the set point, a narrow individual integrator of the stimulation of thyroid hormone production by TSH and negative feedback control of thyroid hormones upon TSH. The interlocking equilibrium of TSH and FT4 result in a kite-shaped distribution of the set points. ${ }^{21}$ Unlike using a fixed TSH target for all patients, it renders the discriminatory TSH threshold between the euthyroid and hypothyroid state variable amongst the individuals in a population and, in an individual, conditionally dependent on paired FT4 concentrations or setpoints. ${ }^{21-22}$
Another regulatory component and chief provider to variation arises from TSH providing feed-forward stimulation of the enzymes deiodinase 1 and 2, regulating T4 to T3 conversion rates to genetically determined individual requirements. ${ }^{23}$ This pathway is important in providing interpersonal T3 stability in thyroid health, rendering $\mathrm{T} 3$ generation to a significant extent independent of T4 supply. Nevertheless, the procedure fails in LT4treated thyroidectomized patients, disturbing the balance between free FT3, FT4, and TSH accordingly, a certain TSH level attained in a healthy person cannot equally oblige as a treatment target for LT4 replacement after the patient has undergone thyroidectomy. ${ }^{24}$

A prior systematic review determined that higher circulating FT4 levels, not TSH levels, were linked to an amplified hazard of incident atrial fibrillation in euthyroids. ${ }^{25}$

Prospective research conducting on LT4treated athyreotic patients with thyroid cancer found that patients with mildly suppressed TSH levels were closest to euthyroid, whereas TSH levels within the reference range were suggestive of tissue hypothyroidism in these patients. ${ }^{26}$

American Thyroid Association conducted a survey study that showed extensive dissatisfaction with standard monotherapy among patients or most thyroid specialists who prefer considered therapies alternative to LT4 treatment in hypothyroid patients. ${ }^{27,28}$

Awareness of being chronically ill with lifelong drug dependency could make patients unhappy and less healthy. Qualitative interview studies show that patients in general have a low understanding of their condition. When they experience hypothyroid symptoms at

\section{$\begin{array}{lllll}\text { The Egyptian Journal of Community Medicine } & \text { Vol. } 39 & \text { No. } 4 & \text { Oct. } & 2021\end{array}$}


initial diagnosis, the perception of disease susceptibility (and adherence to L-T4) is better, but patients who remain unwell despite a normal serum TSH felt that their normal result presented a barrier to further evaluation. $^{29}$

Deteriorating QoL among patients with autoimmune thyroiditis than athyreotic ones in the current study agreed Watt and coauthors $^{30}$ with who concluded that autoimmunity, independent of thyroid function, impairs on QoL in patients with autoimmune hypothyroidism.

The study can be explained in context of some limitations; being cross-sectional study applied in single center. Yet the study had some strength points; all included patients received replacement dose at the same time. The tools used apart from SWLS were thyroid-specific so no need for adding control group and correlating QoL scores to laboratory parameters especially TSH, the hallmark in disease control. Thyroid antibodies were not measured.

We strongly recommend further large scale prospective clinical trials to reach an agreed-upon management strategy that helps hypothyroid patients to lead a healthy life not merely biochemical euthyroid.

\section{Conclusion}

Biochemical well-being not necessarily means physical wellbeing. TSH alone can render patients biochemically euthyroid yet the patients still suffer. Reduced T3/T4 ratio impaired QoL which pointed to importance of development of management starategy rather than relying only on TSH levels.

List of abbreviations: TSH: thyroid stimulating hormone, FT3: free T3, FT4: free $T 4$,

\section{Consent of publications:}

All patients accepted to use their data for research purposes after ensuring confidentiality of their data.

Competing interest: The authors declared no conflict of interest

Funding: The author funded this research on their own.

Author contributions: all authors participated in preparation, writing of manuscript, and interviewing of patients.

\section{Acknowledgement:}

The authors acknowledged patients or their participation in this work

\section{References}

1. Chakera AJ, Pearce SH, Vaidya B. Treatment for primary hypothyroidism: current approaches and future possibilities. Drug Des Devel Ther. 2012;6:1-11.

2. Jonklaas J, Bianco AC, Bauer AJ, et al. Guidelines for the treatment of hypothyroidism: prepared by the American Thyroid Association task force on thyroid hormone replacement. Thyroid. 2014;24:1670-1751

3. Cooper DS, Biondi B. Subclinical thyroid disease. Lancet. 2012; 379:1142-1154.

4. Thvilum M, Brandt F, Almind D, Christensen K, Brix TH, Hegedus L. Type and extent of somatic morbidity before and after thediagnosis of hypothyroidism. a nationwide register study. PLoS One. 2013;8:e75789.

5. Thvilum M, Brandt F, Almind D, Christensen K, Brix TH, Hegedüs L. Increased psychiatric morbidity before and after the diagnosis of hypothyroidism: A nationwide register study. Thyroid 2014;24: 802-808.

6. Watt T, Groenvold M, Rasmussen AK, et al. Quality of life in patients with benign thyroid disorders. A review. Eur J Endocrinol. 2006; 154:501-510.

7. J. Peterson, E.A. McAninch, A.C. Bianco, Is a normal TSH synonymous with "euthyroidism" in levothyroxine monotherapy? J. Clin. Endocrinol. Metab. 2016; 101(12), 4964-4973.

\section{$\begin{array}{lllll}\text { The Egyptian Journal of Community Medicine } & \text { Vol. } 39 & \text { No. } 4 & \text { Oct. } & 2021\end{array}$}


8. Gullo D., Adele Latina., Francesco Frasca, Rosario Le Moli, Gabriella Pellegriti, Riccardo Vigneri. Levothyroxine Monotherapy Cannot Guarantee Euthyroidism in All Athyreotic Patients. PLoS ONE 2011,6(8) e22552

9. El-Gilany A, El-Wehady A, El-Wasify M. Updating and validation of the socioeconomic status scale for health research in Egypt. Eastern Mediterranean Health Journal. 2012; 18 (9):962-8

10.McMillan C, Bradley C, Razvi S, Weaver J Evaluation of New Measures of the Impact of Hypothyroidism on Quality of Life and Symptoms:The ThyDQoL and ThySRQ 8, International Society for Pharmacoeconomics and Outcomes Research (ISPOR) 2008; 2(2): 285-294.

11.McMillan C, Bradley C, Razvi S, Weaver J, Psychometric Evaluation of a New Questionnaire Measuring Treatment Satisfaction in Hypothyroidism: The ThyTSQ. Value in health International Society for Pharmacoeconomics and Outcomes Research (ISPOR)2006;9:2:132-139

12.Diener ED, Emmons RA, Larsen RJ, Griffin S. The satisfaction with life scale. J Pers Assess. 1985;49:71-5

13.Pavot W, Diener E. Review of the satisfaction with life scale. In: Diener E, editor. Assessing well-being: the collected works of Ed Diener. Springer social indicators research series 2009; 39:101-17.

14. Watt T., Cramon P, Hegedüs L, Bjorner J, Bonnema SJ, Rasmussen AK, FeldtRasmussen $U$ The thyroid-related quality of life measure ThyPRO has good responsiveness and ability to detect relevant treatment effects. J. Clin. Endocrinol. Metab 2014; 99(10), 3708-3717.

15.Kalra S, Khandelwal SK. Why are our hypothyroid patients unhappy? Is tissue hypothyroidism the answer?. Indian J Endocrinol Metab. 2011;15(Suppl 2):S95-S98. 16.Molewijk E, Martens M, Fliers E, Zelissen P, Dreijerink K, Dooren AV\& Heerdink R. Reduced quality of life and persistent complaints in treated hypothyroid patients. Endocrine Abstracts (2018) 56 GP274.
Available on: https://www.endocrineabstracts.org/ea/0056/ea0056gp274.htm (last accessed 26 July 2020).

17. Shivaprasad C, Rakesh B, Anish K, Annie P, Amit G, Dwarakanath CS. Impairment of Health-related Quality of Life among Indian Patients with Hypothyroidism. Indian J Endocrinol Metab. 2018;22(3):335-338.

18. Morgunova T., Manuilova Y., Madyarova M., et al. Quality of life in patients with hypothyroidism // Clinical and experimental thyroidology 2010; 6 (2): 62-67.

19. Winther KH, Cramon P, Watt T, Bjorner $\mathrm{JB}$, Ekholm O, Feldt-Rasmussen U, et al. Disease-specific as well as generic quality of life is widely impacted in autoimmune hypothyroidism and improves during the first six months of levothyroxine therapy. PLoS One. 2016;11:e0156925

20.Hoermann R, Midgley JEM, Larisch R, Dietrich JW. Advances in applied homeostatic modelling of the relationship between thyrotropin and free thyroxine. PLoS One. 2017;12:e0187232.

21.Hoermann R, Larisch R, Dietrich JW, Midgley JEM. Derivation of a multivariate reference range for pituitary thyrotropin and thyroid hormones: diagnostic efficiency compared with conventional single-reference method. Eur J Endocrinol. 2016;174:735-743.

22.Castagna MG, Dentice M, Cantara S, et al. Dio2 thr92ala reduces deiodinase-2 activity and serum-T3 levels in thyroid-deficient patients. J Clin Endocrinol Metab. 2017;102:1623-1630.

23.Hoermann R, Midgley JEM, Larisch R, Dietrich JW. Individualised requirements for optimum treatment of hypothyroidism: complex needs, limited options. Drugs Context. 2019;8:212597.

24.Ito M, Miyauchi A, Morita S, et al. TSHsuppressive doses of levothyroxine are required to achieve preoperative native serum triiodothyronine levels in patients who have undergone total thyroidectomy. Eur J Endocrinol. 2012;167:373-378.

25.Baumgartner C, Da Costa BR, Collet TH, et al. Thyroid function within the normal range, 
subclinical hypothyroidism, and the risk of atrial fibrillation. Circulation. 2017;136:21002116

26.Ito M, Miyauchi A, Hisakado M, et al. Biochemical markers reflecting thyroid function in athyreotic patients on levothyroxine

monotherapy. Thyroid. 2017;27:484-490.

27.Peterson SJ, Cappola AR, Castro MR, et al. An online survey of hypothyroid patients demonstrates prominent dissatisfaction. Thyroid. 2018;28:707-721.
28. Jonklaas J, Tefera E, Shara N. Prescribing therapy for hypothyroidism: influence of physician

characteristics. Thyroid. 2019;29:44-52.

29. Wiersinga WM. T4+T3 combination therapy: any progress?. Endocrine. 2019;66(1):70-78.

30. Watt T, Hegedüs L, Bjorner JB, et al. Is Thyroid Autoimmunity per se a Determinant of Quality of Life in Patients with Autoimmune Hypothyroidism?. Eur Thyroid J. 2012;1(3):186-192. 